\title{
Radical Polymerizations of Methyl Methacrylate and of Related Monomers with a Ruthenium Complex- Triphenylphosphine Catalyst
}

\author{
Katsuma Hiraki, Shoichi Kaneko, and Hidefumi Hirai \\ Department of Industrial Chemistry, Faculty of Engineering, \\ University of Tokyo, Hongo, Bunkyo-ku, Tokyo, 113, Japan.
}

(Received November 9, 1970)

\begin{abstract}
Methyl methacrylate, methyl acrylate, and dimethyl itaconate are polymerized in homogeneous solutions with a catalyst derived from dichloro(dodeca-2, 6,10-triene-1,12-diyl)ruthenium(IV) 1 and triphenylphosphine. The polymer yields of these three monomers increase with the increasing molar ratio of triphenylphosphine to 1. 1 itself has stable $\pi$-allylic bonds and yields no polymer. With addition of triphenylphosphine to 1 , the $\pi$-allylic bonds are converted into active $\sigma$-allylic ones, which are considered to participate in the initiation of these polymerizations. On the basis of the tacticity of the resulting poly(methyl methacrylate), of the kinetic investigations on the polymerization of methyl methacrylate, and of the composition of methyl methacrylatestyrene copolymer, it is concluded that the polymerization proceeds through a radical mechanism. The mechanism of the formation of the radical species in the initiation is discussed on the ground of the specificity of the activity for the polymerizations of typical vinyl monomers.
\end{abstract}

KEY WORDS Radical Polymerization / Methyl Methacrylate / Methyl Acrylate / Dimethyl Itaconate / Ruthenium Complex / Triphenylphosphine / $\sigma$-Ally-lic Bond /

Methyl methacrylate(MMA) has been polymerized by use of dichloropalladium(II) complexes, rhodium(III) chloride trihydrate, or hexachloroplatinic(IV) acid hexahydrate in aqueous emulsions. ${ }^{1}$ The polymerizations with these noble metal complexes were reported to proceed through a radical mechanism, on the basis of the tacticity of the resultant polymers and of the composition of MMA-styrene copolymer. ${ }^{1}$ However, little is known about the mechanism of the generation of the radical species in these polymerizations. Alkyl-dichlorochromium(III) was also reported to polymerize MMA through a radical mechanism. ${ }^{2}$

On the other hand, a syndiotactic poly(methyl methacrylate) [poly(MMA)] was obtained with titanium(IV) chloride- or alkyl titanate(IV)-triethylaluminum catalyst at a low temperature. ${ }^{3-5}$ Recently, it has been reported that triallylchromium(III), ${ }^{6,7}$ dialkylbis(dipyridyl)iron(II), ${ }^{8-10}$ and ethylbis(dipyridyl)cobalt(I) ${ }^{8-10}$ polymerized MMA, acrylonitrile, and methacrylonitrile through a coordinated anionic mechanism.

The authors have already reported the homogeneous polymerizations of butadiene ${ }^{11,12)}$ and of norbornene ${ }^{13}$ with a ruthenium complextertiary phosphine catalyst. In addition, this catalyst has been found to polymerize MMA, methyl acrylate(MA), and dimethyl itaconate (DMI) in fairly high yields. This paper will deal with these polymerizations by use of this catalyst and the mechanism of the polymerizations will be presented.

\section{EXPERIMENTAL}

\section{Materials}

Dichloro(dodeca-2, 6, 10-triene-1, 12-diyl)ruthenium(IV) (1) was synthesized in the manner described by Shaw, et al. ${ }^{14}$ The monomers used for polymerization were freed from inhibitors and purified by distillation prior to use. Dichloromethane was dried over anhydrous calcium chloride and distilled. Triphenyl- 


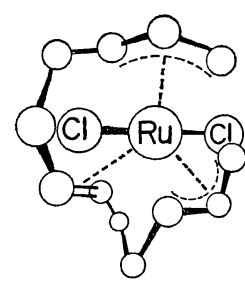

1

phosphine (Tokyo Kasei Kogyo Co.) was used without further purification.

\section{Procedure}

The catalyst components were put into a 25$\mathrm{m} l$ ampoule, which had previously been filled with dry nitrogen. Dichloromethane and the monomer were introduced into the ampoule. The ampoule was connected to a vacuum line, degassed at liquid nitrogen temperature, and sealed off. This ampoule was set in a water bath controlled at a constant temperature. After a predetermined time, the reaction mixture was poured into an excess amount of methanolhydrobromic acid mixture. A sedimented polymer was washed with methanol and dried in vacuo. The polymerization rate $\left(R_{p}\right)$ was calculated from the difference of the polymer yields at the reaction times of 2 and $4 \mathrm{hr}$. As for MA, DMI, and vinyl acetate, petroleum ether was used as the precipitant.

The viscosity-average molecular weight of poly(MMA) was calculated from the intrinsic viscosity measured in acetone at $25^{\circ} \mathrm{C}$, using the following equation ${ }^{15}$

$$
[\eta]=0.96 \times 10^{-4} \times\left[\bar{M}_{v}\right]^{0.69}
$$

That of poly(methyl acrylate) [poly(MA)] was obtained from the intrinsic viscosity measured in benzene at $25^{\circ} \mathrm{C}$, using the following relationship $^{16}$

$$
[\eta]=1.28 \times 10^{-4} \times\left[\bar{M}_{v}\right]^{0.71}
$$

The NMR spectrum of poly(MMA) was measured as a nitromethane solution on a Japan Electron Optics Laboratory's model $4 \mathrm{H}-100$ spectrometer, operating at $100 \mathrm{MHz}$ at $100^{\circ} \mathrm{C}$.

\section{RESULTS}

Table I shows the results of polymerization of MMA with the catalyst derived from 1 and
Table I. Polymerization of MMA with the ruthenium complex-triphenylphosphine

\begin{tabular}{|c|c|c|c|c|}
\hline \multirow[b]{2}{*}{$\begin{array}{l}\mathrm{P} / \mathrm{Ru} \\
\text { ratio }\end{array}$} & \multirow[b]{2}{*}{$\underset{{ }^{\circ} \mathrm{C}}{\text { Temp }}$} & \multicolumn{3}{|c|}{ Polymer obtained } \\
\hline & & $\underset{\%}{\text { Yield, }}$ & $\begin{array}{l}{\left[\bar{M}_{v}\right], \mathrm{b}} \\
\times 10^{-4}\end{array}$ & $\begin{array}{l}\text { Number of } \\
\text { chains, } \\
\text { mol/(mol of } \\
\text { Ru })\end{array}$ \\
\hline 0 & 50 & 0 & & \\
\hline 1 & $" \prime$ & 20.0 & 5.4 & 0.14 \\
\hline 2 & " & 42.3 & 4.1 & 0.39 \\
\hline 5 & " & 68.8 & 3.9 & 0.67 \\
\hline 10 & " & 65.7 & 2.7 & 0.92 \\
\hline 15 & " & 78.2 & 3.7 & 0.80 \\
\hline 20 & $" \prime$ & 76.8 & 4.1 & 0.71 \\
\hline 1 & 30 & 0.1 & & \\
\hline 2 & "I & 8.7 & 5.6 & 0.08 \\
\hline 5 & " & 19.7 & 3.6 & 0.21 \\
\hline 10 & $\prime \prime$ & 22.9 & 7.4 & 0.17 \\
\hline$-^{d}$ & 50 & 0 & & \\
\hline
\end{tabular}
catalyst ${ }^{a}$

a 1, $0.10 \mathrm{mmol}$; MMA, $4.0 \mathrm{ml}$; dichloromethane, $8.0 \mathrm{ml}$; reaction time, $24 \mathrm{hr}$.

b Calculated from the intrinsic viscosity, using eq 1.

c Calculated from the yield and $\left[\bar{M}_{v}\right]$.

d Blank test by use of $0.20 \mathrm{mmol}$ of triphenylphosphine, without 1.

triphenylphosphine. The yield of poly(MMA) increases with a molar ratio of triphenylphosphine to $\mathbf{1}(\mathrm{P} / \mathrm{Ru}$ ratio) and shows a considerably high yield at the $\mathrm{P} / \mathrm{Ru}$ ratios of 5 to 20 , at $50^{\circ} \mathrm{C}$. The polymer yield at $30^{\circ} \mathrm{C}$ is smaller than that at $50^{\circ} \mathrm{C}$ at the same $\mathrm{P} / \mathrm{Ru}$ ratio. Table II exhibits both the tacticity of the poly(MMA) yielded with this catalyst, and a $\sigma$-value calculated from the syndiotactic content of the polymer, using Bovey and Tiers' relationship. ${ }^{17}$ The $\sigma$-value was virtually identical with that of poly(MMA) obtained with an usual radical initiator. ${ }^{17}$ The isotactic and the heterotactic contents of the polymer corresponded fairly well to the respective values calculated from the $\sigma$-value, using Bovey and Tiers' relationship.

The kinetic analysis on this polymerization at the $P / R u$ ratio of 5 has been carried out. As seen in Figure 1, the polymer yield increases gradually in progress of the reaction time. Figure 2 shows the plot of $\log M_{0} /\left(M_{0}-Y\right)$ against the reaction time, where $M_{0}$ and $Y$ mean 


\section{Radical Polymerization with Ruthenium Complex}

Table II. Tacticitya of Poly(MMA) obtained with the ruthenium complex-triphenylphosphine catalyst

\begin{tabular}{|c|c|c|c|c|c|c|c|}
\hline \multirow{3}{*}{$\begin{array}{l}\mathrm{P} / \mathrm{Ru} \\
\text { ratio }\end{array}$} & \multirow{3}{*}{$\underset{{ }^{\circ} \mathrm{C}}{\text { Temp }}$} & \multicolumn{5}{|c|}{$\begin{array}{c}\text { Tacticity of poly(MMA), } \\
\%\end{array}$} & \multirow{3}{*}{$\sigma^{\mathrm{b}}$} \\
\hline & & \multicolumn{3}{|c|}{ Found } & \multicolumn{2}{|c|}{ Calcd $^{\mathrm{c}}$} & \\
\hline & & $S$ & $I$ & $H$ & $I$ & $H$ & \\
\hline 1 & 50 & 65 & 6 & 29 & 4 & 31 & 0.20 \\
\hline 2 & " & 61 & 8 & 31 & 5 & 34 & 0.22 \\
\hline 5 & " & 59 & 6 & 35 & 6 & 35 & 0.23 \\
\hline 10 & " & 60 & 7 & 33 & 6 & 34 & 0.23 \\
\hline 15 & " & 51 & 8 & 41 & 8 & 41 & 0.28 \\
\hline 20 & $"$ & 56 & 9 & 35 & 6 & 38 & 0.26 \\
\hline 2 & 30 & 69 & 6 & 28 & 3 & 28 & 0.17 \\
\hline 5 & " & 64 & 4 & 32 & 4 & 32 & 0.20 \\
\hline 10 & " & 66 & 5 & 29 & 4 & 30 & 0.19 \\
\hline
\end{tabular}

a Calculated from the NMR spectrum of poly(MMA), according to the method of Bovey and Tiers. ${ }^{17}$

${ }^{b}$ Calculated from the syndiotactic content of the poly(MMA), using Bovey and Tiers' relationship. ${ }^{17}$

c Calculated from the $\sigma$-value, using the Bovey and Tiers' relationship.

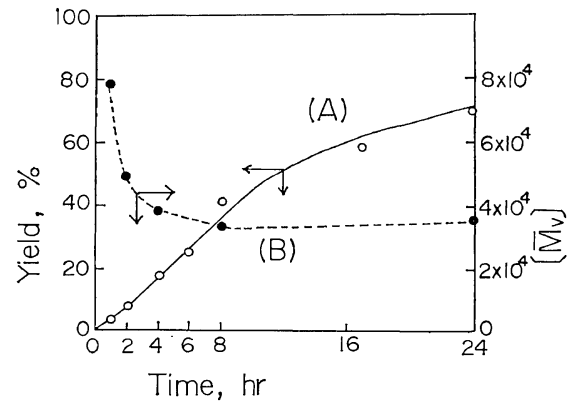

Figure 1. Polymerization of MMA initiated by the ruthenium complex-triphenylphosphine catalyst: $\mathrm{R} / \mathrm{Ru}$ ratio, $5 ; M_{0}, 3.15 \mathrm{~mol} / l$; initial concentration of $1,8.3 \times 10^{-3} \mathrm{~mol} / l$; at $50^{\circ} \mathrm{C} ; \mathrm{A}(-\bigcirc-)$, polymer yield; B (------), the viscosity-average molecular weight of the polymer.

the concentration of MMA at the initial stage and that of the monomer consumed till time $t$, respectively. The value of $\log M_{0} /\left(M_{0}-Y\right)$ is virtually linear to the reaction time. This fact and Figure 3 indicates that the polymerization rate of MMA is proportional to the first order of the concentration of the monomer. In addition, the polymerization rate at the constant

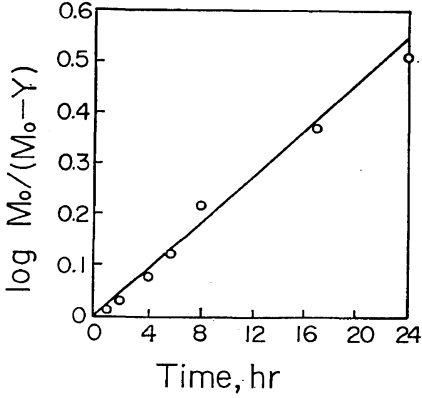

Figure 2. Plots of $\log M_{0} /\left(M_{0}-Y\right)$ against the reaction time. The values of $M_{0}$ and of $Y$ were used from the data in Figure 1.

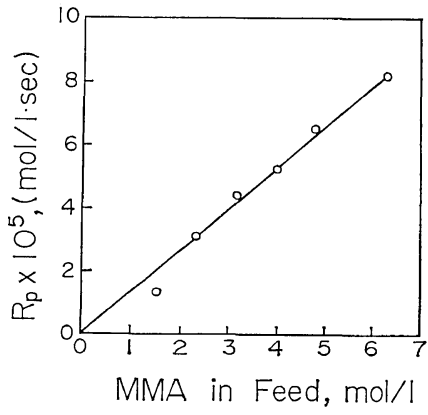

Figure 3. Effect of the initial concentration of MMA upon the polymerization rate: at $50^{\circ} \mathrm{C}$; $\mathrm{P} / \mathrm{Ru}$ ratio, 5; Initial concentration of $1,8.3 \times$ $10^{-3} \mathrm{~mol} / l$.

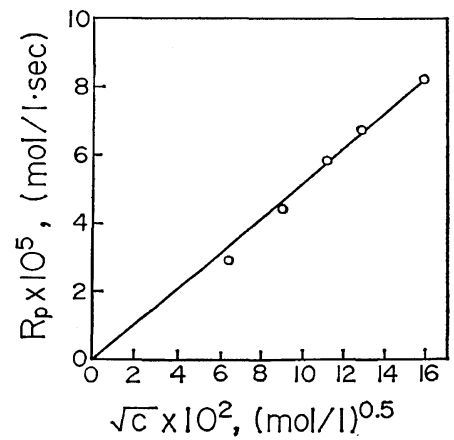

Figure 4. Dependency of the polymerization rate on the concentration of $1: M_{0}, 3.15 \mathrm{~mol} / l ; \mathrm{P} / \mathrm{Ru}$ ratio, 5 ; at $50^{\circ} \mathrm{C}$.

$\mathrm{P} / \mathrm{Ru}$ ratio is proportional to the square root of the concentration of $\mathbf{1}$, as shown in Figure 4. Accordingly, the polymerization rate in this case can be represented by the following equation 


$$
R_{p}=-\frac{\mathrm{d} M}{\mathrm{~d} t}=k \cdot C^{1 / 2} \cdot M
$$

where $M$ and $C$ are the concentration of the monomer and that of $\mathbf{1}$ at time $t$, respectively, at the $P / R u$ ratio of 5 . This relationship is quite consistent with that of the usual radical polymerization. ${ }^{18}$ The viscosity-average molecular weight of the resulting polymer was about $7.8 \times 10^{4}$ in the earlier stage of the polymerization, and decreased to $3.2 \times 10^{4}$ in progress of the reaction time (Figure 1).

Table III shows the results of polymerization

Table III. Polymerization of MA and of DMI with the ruthenium complex-triphenylphosphine catalyst ${ }^{\mathrm{a}}$

\begin{tabular}{lrccc}
\hline & & \multicolumn{3}{c}{ Polymer obtained } \\
\cline { 3 - 5 } Monomer & $\begin{array}{c}\text { P/Ru } \\
\text { ratio }\end{array}$ & $\begin{array}{c}\text { Yield, } \\
\%\end{array}$ & $\begin{array}{c}{\left[\bar{M}_{v}\right],{ }^{\mathrm{b}}} \\
\times 10^{-4}\end{array}$ & $\begin{array}{c}\text { Number of } \\
\text { chains, } \\
\text { mol } /(\mathrm{mol} \text { of } \\
\text { Ru })\end{array}$ \\
\hline MA & 2 & 1.9 & & \\
MA & 5 & 20 & 27 & 0.03 \\
MA & 10 & 32 & 19 & 0.06 \\
MA & 15 & 37 & 16 & 0.09 \\
DMI & 2 & 4.1 & & \\
DMI & 5 & 6.6 & & \\
DMI & 10 & 10.1 & & \\
\hline
\end{tabular}

a $1,0.10 \mathrm{mmol}$; monomer, $4.0 \mathrm{ml}$; dichloromethane, $8.0 \mathrm{ml}$; reaction time, $24 \mathrm{hr}$; at $50^{\circ} \mathrm{C}$.

b Calculated from the intrinsic viscosity, using eq 2.

c Calculated from the yield and $\left[\bar{M}_{v}\right]$.

runs of MA and DMI with the ruthenium complex-triphenylphosphine catalyst. The yields of poly(MA) and of poly(dimethyl itaconate) increased with the $\mathrm{P} / \mathrm{Ru}$ ratio, analogously to that of poly(MMA), and were smaller than that of poly(MMA) at the same $\mathrm{P} / \mathrm{Ru}$ ratio. The viscosity-average molecular weight of poly(MA) was larger than that of poly(MMA). This indicates that the number of polymer chains of the former polymer per ruthenium atom was considerably smaller than that of the latter polymer.

The ruthenium complex-triphenylphosphine catalyst gave only yields less than $2 \%$ of polymers of styrene, of vinyl acetate, and of ethyl vinyl ether. Acrylonitrile, methyl vinyl ketone, ethyl sorbate, and vinyl chloride did not produce polymers at all with this catalyst. However, this catalyst at the $P / R u$ ratio of 5 produced copolymers of MMA with styrene in $5-15 \%$ yields. Figure 5 shows the contents of

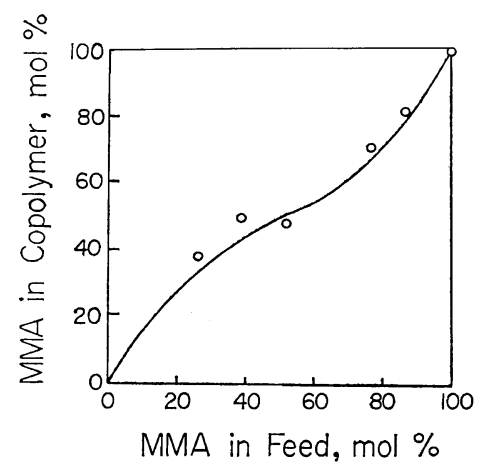

Figure 5. Composition curve of the MMAstyrene copolymer obtained with the ruthenium complex-triphenylphosphine catalyst: $\mathbf{1}, \quad 0.10$ $\mathrm{mmol} ; \mathrm{P} / \mathrm{Ru}$ ratio, 5 ; monomer, $4.0 \mathrm{ml}$; dichloromethane, $8.0 \mathrm{ml}$; at $50^{\circ} \mathrm{C} ; \bigcirc$, experimental data; -, data obtained with the usual radical initiators. ${ }^{19}$

MMA in the copolymers, which were obtained in yields less than 11\%. The contents of MMA in the copolymers are in accordance with the composition curve of the copolymer obtained with the usual radical initiators. ${ }^{19}$

\section{DISCUSSION}

Dichloro(dodeca-2, 6, 10-triene-1, 12-diyl)ruthenium(IV) has considerably stable $\pi$-allylic bonds, and is quite inactive for the polymerization of MMA, similar to the case of butadiene. ${ }^{11,12}$ The NMR spectra of the 1-triphenylphosphine system indicated that the $\pi$-allylic bonds in 1 were converted into active $\sigma$-allylic ones with an addition of two moles of triphenylphosphine. ${ }^{11,12}$ On the basis of this evidence and the correlation between the yield of poly (MMA) and the $P / R u$ ratio (Table $I$ ), it is reasonable to assume that the $\sigma$-allylic bonds in the 1 -triphenylphosphine system participate in the initiation reaction of the polymerization.

It is noteworthy that the ruthenium complextriphenylphosphine catalyst displayed very specific 
activity in the polymerizations of MMA, MA, and DMI, which have moderate $e$-values. In addition, it may be concluded that a propagation reaction in the polymerization of MMA proceeds through a radical mechanism, on the basis of the tacticity of the resulting poly(MMA) (Table II), of the composition curve of the MMAstyrene copolymer (Figure 5), and of the dependency of the polymerization rate upon the concentration of the catalyst (Figure 4). Mao, et al.,$^{20}$ reported that a radical polymerization of MMA was induced by a photochemical excitation of a charge-transfer complex between the monomer and triphenylphosphine. However, in this study, this type of initiation was negligible, because no polymer of MMA was produced only with triphenylphosphine under present conditions (see a blank test in Table I), and because there was virtually no difference between the polymer yields under the usual conditions and the one carried out in the ampoule shielded from light with aluminum foil.

A vinyl monomer with an electron-attracting substituent is capable of coordinating to an alkyltransition metal complex, which is stabilized by donors. The coordinated monomer activates the alkyl-transition metal bond, leading to the splitting of the alkyl-transition metal bond or to polymerization of the monomer. ${ }^{8-10,21}$ On the other hand, a vinyl monomer with a low $e$-value, such as styrene, vinyl acetate, vinyl chloride, and alkyl vinyl ether, was not polymerized by the alkyl-transition metal complex coordinated with donors, ${ }^{8-10}$ presumably owing to the lack of coordination ability of the monomer to the central metal. The ruthenium complex-triphenylphosphine catalyst has only little or no activity for polymerization of styrene, vinyl acetate, vinyl chloride, and ethyl vinyl ether, whereas the former three monomers are known to be polymerized easily through the radical mechanism.

Acrylonitrile and methyl vinyl ketone, which have stronger electron-attracting groups than MMA or MA, interact directly with triphenylphosphine, ${ }^{22-24}$ and probably with the ruthenium complex. These interactions interrupt the coordination of triphenylphosphine to $\mathbf{1}$, and accordingly, inhibit virtually both the conversion of the $\pi$-allylic bonds in 1 into the $\sigma$-allylic ones and the polymerization of these two monomers.

In view of these facts and of the factors discussed above, the vinyl monomer with the alkoxycarbonyl group, like MMA, MA, or DMI, may be coordinated with the $\sigma$-allylic ruthenium complex present in the 1-triphenylphosphine system, and may activate the $\sigma$-allyl-ruthenium bonds. The activated bonds may be converted into allylic radical species, as shown in eq 4 ,

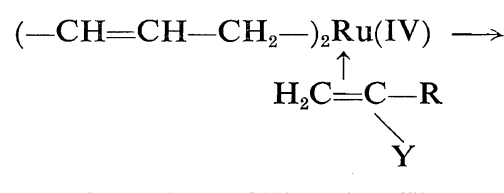

$$
2-\mathrm{CH}=\mathrm{CH}-\mathrm{CH}_{2} \cdot+\mathrm{Ru}(\mathrm{II})
$$

where $\mathrm{R}$ is $\mathrm{H}, \mathrm{CH}_{3}$, or $\mathrm{CH}_{2} \mathrm{COOCH}_{3}$, and $\mathrm{Y}$ is $\mathrm{COOCH}_{3}$. In fact, dichlorotris(triphenylphosphine)ruthenium(II), which has no carbonruthenium bond, produced virtually no polymer of MMA. This mechanism is also consistent with the fact that diethyl(dipyridyl)nickel(II) and diethylbis(dipyridyl)iron(II) at high concentration reacted with the vinyl monomer with the electron-attracting group, and were reduced to a zero valent state yielding butane ${ }^{25}$ and an ethane-ethylene mixture, ${ }^{21}$ respectively. Ethyl sorbate, i. e., ethyl trans- $\beta$-substituted acrylate, gave no polymer with the ruthenium complextriphenylphosphine catalyst. This indicates that this monomer is presumably unable to coordinate with the alkyl-transition metal complex.

The optimum $\mathrm{P} / \mathrm{Ru}$ ratios for the yields of poly(MMA) and of poly(MA) were considerably larger than those for polybutadiene ${ }^{11,12}$ and polynorbornene. ${ }^{13}$ This is possibly due to an interaction of triphenylphosphine with MMA or with MA. Indeed, it has already been reported that MA interacts with triphenylphosphine. ${ }^{24}$

\section{CONCLUSION}

(1) The catalyst derived from dichloro(dodeca-2,6,10-triene-1,12-diyl)ruthenium(IV) and triphenylphosphine was found to polymerize MMA, MA, and DMI in homogeneous solution.

(2) The kinetic behavior of the polymerization of MMA, the tacticity of poly(MMA), and the copolymerization between MMA and styrene were examined. 
(3) The propagation in the polymerization of MMA is considered to proceed through a radical mechanism.

Acknowledgement. The authors wish to thank Mr. Masayuki Kunugi for the measurement of the NMR spectrum of poly(MMA).

\section{REFERENCES}

1. R. S. Berger and E. A. Youngman, J. Polym. Sci. Part A, 2, 357 (1964).

2. S. Ikeda, H. Kuribayashi, and A. Yamamoto, Preprint II, SPSJ 18 th Annual. Meeting, Kyoto, 1969, p. 301.

3. H. Abe, K. Imai, and M. Matsumoto, J. Polym. Sci., Part B, 3, 1053 (1965).

4. H. Abe, K. Imai, and M. Matsumoto, ibid, 4, 589 (1966).

5. N. Koide, K. Iimura, and M. Takeda, Kogyo Kagaku Zasshi (J. Chem. Soc. Japan, Chem. Ind. Sect.), 70, 1224 (1967).

6. D. G. H. Ballard, W. H. Janes, and T. Medinger, J. Chem. Soc., (B), 1168 (1968).

7. D. G. H. Ballard and T. Medinger, ibid, 1178 (1968).

8. A. Yamamoto and S. Ikeda, J. Amer. Chem., Soc., 89, 5989 (1967).

9. A. Yamamoto, T. Shimizu, and S. Ikeda, Preprints I, SPSJ 18 th Symposium on Macromolecules, Tokyo, 1969, p. 215.

10. A. Yamamoto, T. Shimizu, and S. Ikeda, Polymer J., 1, 171 (1970).

11. K. Hiraki and H. Hirai, J. Polym. Sci., Part
$B, 7,449$ (1969).

12. K. Hiraki and H. Hirai, Maciomolecules, 3, 382 (1970).

13. K. Hiraki, A. Kuroiwa, and H. Hirai, Abstracts, 23 rd Annual Meeting of Chemical Society of Japan, Tokyo, 1970, p. 2030.

14. J. E. Lydon, J. K. Nicholson, B. L. Shaw, and M. R. Truter, Proc. Chem. Soc., 421 (1964).

15. S. Chiani, J. Matlack, and A. Resnick, J. Polym. Sci., 17, 391 (1955).

16. S. Basu and H. Roy, J. Sci. Ind., Res., 11B, 90 (1952); Chem. Abstr., 46, 7847 (1952).

17. F. A. Bovey and G. V. D. Tiers, J. Polym. Sci., 44, 173 (1960).

18. P. J. Flory, "Principles of Polymer Chemistry," Cornell University Press, New York, N. Y., 1953, Chapter 4.

19. F. M. Lewis, F. R. Mayo, and W. F. Hulse, J. Amer. Chem. Soc., 48, 763 (1952).

20. T. J. Mao and R. J. Eldred, J. Polym. Sci., Part A-1, 5, 1741 (1967).

21. T. Yamamoto, A. Yamamoto, and S. Ikeda, Abstracts, 23 rd Annual Meeting of Chemical Society of Japan, Tokyo, 1970, p. 1226.

22. L. Horner, W. Jurgeleit, and K. Kluphel, Liebigs Ann, 591, 108 (1955).

23. C. C. Price and N. Takashina, J. Amer. Chem. Soc., 84, 489 (1962).

24. R. Oda, S. Tanimoto, and T. Kawabata, Tetrahedron Letters, 1653 (1964).

25. T. Yamamoto, A. Yamamoto, and S. Ikeda, Preprints, The Symposium on Organometallic Compounds, Japan, Osaka, 1969, p. 140. 